\title{
Superficial and Deep Skin Preparation with Povidone-lo- dine for Ventriculoperitoneal Shunt Surgery : A Technical Note
}

\author{
Claudia L. Craven, M.Sc., M.R.C.S., Simon D. Thompson, M.Sc., Ahmed K. Toma M.D., F.R.C.S. (SN), \\ Laurence D. Watkins, M.A, F.R.C.S. (SN) \\ Victor Horsley Department of Neurosurgery, National Hospital for Neurology and Neurosurgery, Queen Square, London, UK
}

Objective : Ventriculoperitoneal (VP) shunt surgery is a common and effective treatment for hydrocephalus and cerebrospinal fluid disorders. Infection remains a major cause of morbidity and mortality after a VP shunt. There is evidence that a deep skin flora microbiome may have a role to play in post-operative infections. In this technical note, we present a skin preparation technique that addresses the issue of the skin flora beyond the initial incision.

Methods : The patient is initially prepped, as standard, with a single layer of $2 \% \mathrm{CHG}+70 \%$ isopropyl alcohol. The novel stage is the 'double incision' whereby an initial superficial incision receives a further application of povidone-iodine prior to completing the full depth incision.

Results : Of the 84 shunts inserted using the double-incision method (September 2015 to September 2016), only one developed a shunt infection.

Conclusion : The double incision approach to skin preparation is a unique operative stage in VP shunt surgery that may have a role to play in reducing acute shunt infection.

Key Words : Wound infection, Surgical · Ventriculo-peritoneal shunt · PVP-lodine · Skin · Surgical incision.

\section{INTRODUCTION}

Ventriculoperitoneal (VP) shunt surgery remains the primary procedure to treat hydrocephalus and cerebrospinal fluid (CSF) disorders. Complications from VP shunt insertion include subdural empyemas, brain abscesses and infection which could result in implant colonisation and potentially fatal meningitis ${ }^{20}$. This can result in prolonged treatment with antibiotics in addition to multiple procedures. Often complete removal of the shunt is indicted, with subsequent insertion of an external ventricular drain or lumbar drain (LD) and the eventual replacement of the shunt. Therefore it is of paramount importance that introduction of infection during the primary procedure is avoided. Whilst innovations and techniques to reduce the rate of shunt infection are continuously being developed, the incidence of VP shunt infection in adults

- Received : November 8, 2017 •Revised : December 28, 2017 •Accepted : January 21, 2018

- Address for reprints : Claudia L. Craven, M.Sc, M.R.C.S.

Victor Horsley Department of Neurosurgery, National Hospital for Neurology and Neurosurgery, Queen Square, London WC1N 3BG, UK

Tel : +44-2034567890, Fax : +44-2034483340, E-mail : claudia.craven@gmail.com

This is an Open Access article distributed under the terms of the Creative Commons Attribution Non-Commercial License (http://creativecommons.org/licenses/by-nc/4.0) which permits unrestricted non-commercial use, distribution, and reproduction in any medium, provided the original work is properly cited. 
is remains high with an average of $6 \%$, ranging from 1.6$12.0 \% \%^{3,8,16,19,27)}$.

Intraoperative contamination of the wound is a main source of VP shunt infection ${ }^{3,8,19,28)}$. Skin preparation is an important stage in maintaining a sterile surgical site. Commonly used skin preparation agents include the aqueous-based iodophors, such as povidone-iodine (PVP-I) and polybiganides such as chlorhexidine-gluconate $(\mathrm{CHG})$ often commercial available combined with alcohol-based agents such as ethyl and isopropyl alcohol (IPA) (for example 2\% CHG and 70\% IPA). In this technical note, we describe a single-centre's skin preparation methods during VP shunt insertion, specifically focusing on the 'double incision' and application of PVP-I.

\section{MATERIALS AND METHODS}

\section{Population}

Patients included were aged over 18 years, requiring a VP shunt insertion, or major shunt revision (involving replacement at least the proximal shunt catheter) at a single centre over a 1-year period (September 2015 to September 2016).

\section{Intervention}

\section{Chlorhexidine stage}

A single layer of 2\% CHG+70\% isopropyl alcohol (Chloraprep ${ }^{\circledR}$, Franklin Lakes, NJ, USA) is applied to the surgical site and allowed to dry (usually takes around 3 minutes to dry fully).

\section{Draping stage}

Op-tape and drapes are applied. Ioban ${ }^{\mathrm{TM}}\left(3 \mathrm{M}^{\mathrm{TM}}\right.$, Bracknell,
UK) drape is applied over any the surgical site, from the scalp down to the abdomen ${ }^{7)}$. The site is ready for the initial incision and skin preparation.

\section{First incision}

A very superficial $<1 \mathrm{~mm}$ deep parieto-occipital incision is performed, and a linear abdominal incision (Fig. 1A).

\section{The Betadine ${ }^{\varpi}$ stage}

A 7.5\% PVP-I (Betadine ${ }^{\circledR}$, Stamford, CT, USA) PVP-I soaked gauze is applied to the scalpel (or alternatively change the scalpel blade) and PVP-I is also applied to the incision site (Fig. 1B). The gauze is left over the site for 1 minute. The surgeon then proceeds to complete the full incision (Fig. 1C). The 'double incision' technique overall adds less than 2 minutes to any standard protocol.

\section{Comparison}

The 'double incision' technique was consistently performed or supervised by one of two consultant neurosurgeons with a specialist interest in hydrocephalus. In contrast, we review shunts inserted outside of the specialist team, where the standard 'single incision' technique was confirmed to be used in operative notes. The surgeons at this single centre adhere to a standardised protocol for shunt insertion, whereby number of staff in theatre is minimised, laminar flow is used and intraoperative antibiotics are given.

\section{Outcome}

Shunt infection was defined using the BASICS trial criteria of 'definite' infection : "significant culture of organisms from CSF with organisms grown on primary culture or repeated
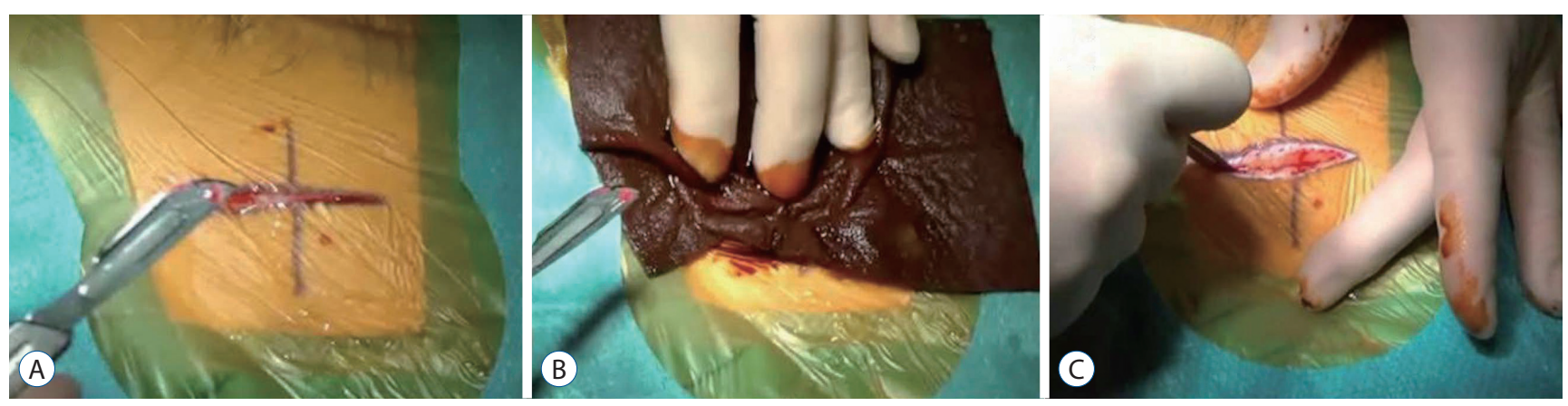

Fig. 1. A : Superficial incision. B : PVP-I soaked gauze is applied to the scalpel and the superficial incision for 1 minute. C : PVP-I is applied to the second incision. PVP-I : povidone-iodine. 
$(>1)$ subculture, with or without clinical signs of infection or malfunction, and managed by shunt removal and antibiotic treatment"16). Chi squared analysis compared the 'double-incision' technique to the standard 'single-incision' method.

\section{RESULTS}

\section{Demographics}

Of the VP shunts inserted over the 1 year period, 127 shunts were inserted or significantly revised (proximal component) of which 84 had 'double incision' method and 43 had standard 'single incision', in patients aged of $61.0 \pm 22.6$ years (mean \pm standard deviation). Indication for shunt insertion is presented in Table 1.

\section{Infection rate}

Of the VP shunts inserted using the double-incision method $(n=84)$ which only one developed a VP shunt infection. This patient's infection was managed with IV antibiotics and shunt removal. In comparison shunts inserted outside of the specialist hydrocephalus team using the 'standard-incision' technique ( $n=43$ ) had two infections, double the rate of infection, albeit not significantly different $(p=0.27)$.

\section{Natural history of shunt infections}

All three infections were insidious, taking over 8 weeks to present and occurred in patients under the age of 40 years. The infected shunt case in the 'double incision' group was 28 years old and had idiopathic intracranial hypertension, diabe- tes, borderline personality disorder and was also a relapsing heroin addict, therefore presenting multiple risk factors. Furthermore, the shunt reservoir was accessed after the 8 weeks, a procedure which may also have introduced infection. They grew Staphylococcus aureus (S. aureus) and Acinetobacter baumannii. One patient in the standard 'single incision' group had an infected pseudomeningocoele and wound breakdown, and one had hydrocephalus secondary to a tumour, with friable thin skin due to radiotherapy. One patient grew $S$. aureus and one S. epidermidis. All patients were treated with shunt removal and antibiotics.

\section{DISCUSSION}

We have described a single centre method of preparation during VP shunt surgery in which a superficial incision receives a further application of PVP-I prior to completing the full incision depth (Fig. 2). The double incision approach to skin preparation is an operative stage in VP shunt surgery that we believe is relatively unique, and may have a role to play in reducing acute shunt infection. The rationale for the double incision skin preparation method is as follows : a proportion of bacteria may have survived the initial skin preparation. Following the initial incision, any remaining organisms have potential to contaminate the deeper dermal layer. Therefore the re-application of PVP-I, both to the wound, and to the scalpel blade, reduces the risk of implanting these bacteria into the deeper tissues layers. The mechanism of action may be amplified by the mechanical washing action from the extra application of PVP-I. This ra-

Table 1. Demographics

\begin{tabular}{lcc}
\hline & Double incision $\mathbf{( n = 8 4 )}$ & Standard incision $(\mathbf{n = 4 3 )}$ \\
\hline Normal pressure hydrocephalus & 20 & 4 \\
\hline Obstructive hydrocephalus (secondary to tumour) & 17 & 14 \\
Obstructive hydrocephalus (secondary to haemorrhage) & 11 & 16 \\
Idiopathic intracranial hypertension & 15 & 2 \\
Chiari malformation & 5 & 0 \\
CSF leak or pseudomeningocoele & 5 & 2 \\
Aqueduct stenosis or longstanding overt ventriculomegaly & 4 & 1 \\
Congenital hydrocephalus & 4 & 2 \\
Post-infective or inflammatory & 3 & 2 \\
\hline
\end{tabular}

CSF : cerebrospinal fluid 


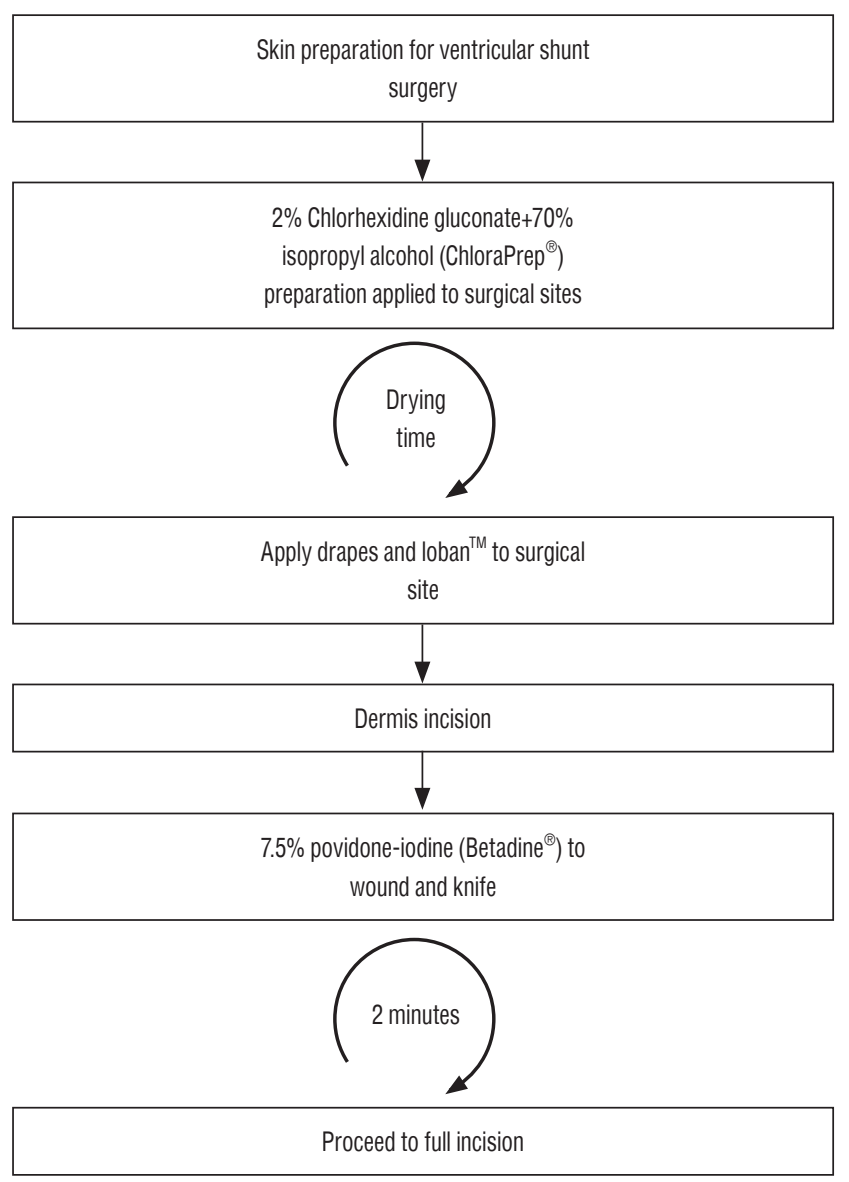

Fig. 2. Skin preparation protocol for VP shunt insertion. VP : ventriculoperitoneal.

tionale is summarised in Fig. 3. The following literature review explores and expands upon this rationale for using a second application of PVP-I to the initial incision.

\section{Mechanism of action of PVP-I and CHG-alcohol}

In this technical report we describe the initial use CHG-alcohol in the initial skin preparation, followed by PVP-I for the double incision skin preparation. CHG-alcohol is known to be fast and an effective broad-spectrum bacteriocidal agent that disrupts bacterial cell membranes ${ }^{21)}$. It has a rapid action, a long duration of 48 hours and there is strong evidence for its effectiveness in preventing surgical site infections ${ }^{5,14)}$. However it has been found to have have long-lasting neuro-toxic effects in some in-vivo studies ${ }^{2,12,13,15)}$.

PVP-I can be used copiously and safely on scalp wounds where the neural structures or meninges may be encountered. Povidone-iodine (PVP-I) is part of the microbiocidal halogens, commonly used as an antiseptic and disinfectant ${ }^{21}$.
(A)
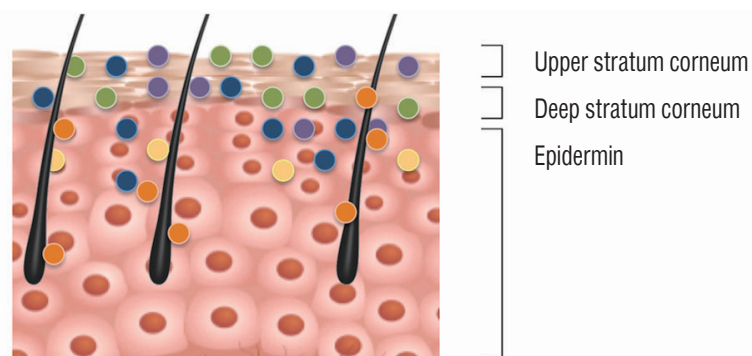

(B)

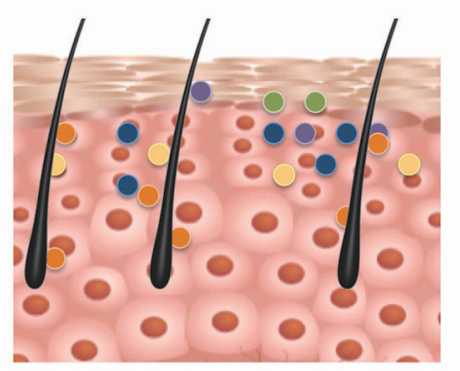

Staphylococcaceae

Propionibacterium

Corynebacterium

Pseudomonas

Non-bacterial organisms
(C)

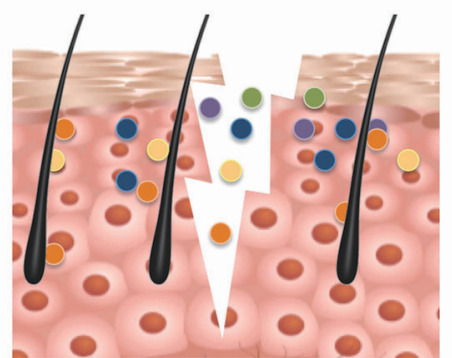

(D)

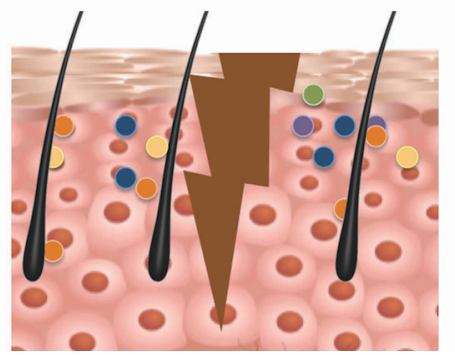

Fig. 3. A : Bacteria populating the superfical (upper stratum corneum) and deep layers (deep stratum corneum, epidermal layers and dermis). B : Elimination of the majority of surface organisms with the application of CHG-alcohol. C : First incision (superficial, less than $1 \mathrm{~mm}$ ), into which deeper organisms that survived the initial CHG-alcohol application. D : Reduction of implanting microbes to deeper layers following application of PVP-I (due to anti-microbial properties and the added irrigation effect). CHG : chlorhexidine-gluconate, PVP-I : povidone-iodine.

PVP-I is an iodophor (also known as iodine-releasing agent) consisting of a complex of iodine and a solubilising agent that allows for the release of free iodine ${ }^{211}$. It is broad-spectrum and is bacteriocidal. Unlike CHG-alcohol, PVP-I is also fungicidal, tuberculocidal, virucidal, sporocidal, in addition to killing protozoa $^{21)}$. 


\section{The surface microbiome}

The parieto-occipital C-shaped scalp incision is near the posterior auricular region, an area abundantly colonised (over 80\%) with Actinobacteria and Propionibacterium species and, to a lesser extend Staphylococcus species ${ }^{10)}$ (Fig. 3). These organisms have all been found to be present in CSF infections after VP shunts insertion, suggesting the spread is from skin, via the shunt, to $\mathrm{CSF}^{26)}$. Organisms such as Propionibacterium acnes (P. acnes) are not only known to cause CSF infection, but also can seed, spread haematogenously and can result in biofilm formation, causing them to be particularly difficult to treat and often resulting in removal of the implanted device $^{1,13)}$. To minimise the number of surface bacteria in our practice, CHG-alcohol is initially applied. Despite the use of both CHG-alcohol, some bacteria may still persist, or become introduced during the superficial incision. We therefore apply the additional layer of PVP-I to reduce implanting bacteria into the deeper tissues layers.

\section{The deeper microbiome}

There is also evidence that there are organisms present within the deeper skin layers, thus providing further justification to a reapplication of PVP-I after the initial superficial incision. Commonly offending organisms causing shunt infections can be found within deeper layer of the stratum corneum, including Staphylococcus aureus, coagulase negative Staphylococcus, $P$. acnes and Corynebacterium ${ }^{6,8,10-13,20,25,28,29)}$ (Fig. 3). The effect of the microbiome can reach as deep as the dermis and there is even evidence of organisms influencing cells below the level of the basement membrane ${ }^{22}$. This sub-epidermal microbiome was found to be diverse and high in Pseudomonas species and Propionibacterium species, both of which are notorious for forming biofilms ${ }^{13,22)}$.

As sebaceous structure, the deeper layers of the scalp also provides an environment for other non-bacterial organisms including viruses, fungi and even small arthropods to reside, such as within the hair shaft, sweat glands, pores and sebaceous glands $^{18)}$ (Fig. 3). Fungal organisms were found to be the cause of $17 \%$ of all infections following paediatric VP shunt insertions $^{4)}$. CSF cultures after VP shunt infections have detected numerous bacteria, both anaerobic and aerobic, and fungal species, suggesting the contamination is occurring at more than just a superficial skin level ${ }^{25)}$. Broad spectrum antiseptics, such as PVP-I, would be effective on the majority of these organisms.

\section{Advantages and disadvantages of double incision skin preparation}

The additional step described in this technical note adds negligible time to the overall procedure, at no extra cost. The method is safe and simple to implement into usual practise. In laboratory practises PVP-I is not very active in exposed tissues (due to cross reactivity with blood). In practise, the copious use of PVP-I negates this effect, and the superficial incision is more often a bloodless field ${ }^{9)}$. There are some instances where PVP-I may not be suitable, for example in patients with a known iodine allergy. No serious iodine associated complications have been reported since using this technique.

\section{Protocol implementation and marginal gain}

There is evidence to show that regular implementation of operating protocols can reduce infection rates in VP shunt surgery ${ }^{17,23)}$. This units protocol includes : consistent sequential operative states, reducing operating theatre traffic, maintaining a consist scrub and anaesthetic team, double gloving, rigid skin preparation methods (as described in this technical note), keeping shunt components within packaging until just prior to insertion, soaking the valve component in vancomycin and the use of intraoperative antibiotics. The concept of marginal gains is important here. We expect each stage to contribute to reducing the incidence of surgical site infection.

\section{Future research}

In light of the high significance of shunt complications, any potentially beneficial innovations and operative steps (such as the double incision and skin preparation method described) should be studied further. There are various randomised controlled trials that have been or are currently being performed, studying protocols and methods to reduce infection after shunt insertion ${ }^{16,17,23,24,26)}$. Infection rates after VP shunt insertion still high, suggesting continued efforts to understand and prevent VP shunt infections is needed ${ }^{3,8,16,19,27)}$. A wide variety of organisms have been detected in CSF infections, including aerobic, anaerobic and fungal species ${ }^{26)}$. Emerging evidence on the human skin microbiome may help target treatments and preventative measures ${ }^{1,10,18,29)}$. 


\section{CONCLUSION}

This double incision skin preparation technique is a simple, quick and unique operative stage in VP shunt surgery that we believe may have an important role in contributing to overall reduction in postoperative infection.

\section{CONFLICTS OF INTEREST}

No potential conflict of interest relevant to this article was reported.

\section{INFORMED CONSENT}

Informed consent was obtained from all individual participants included in this study.

\section{References}

1. Achermann Y, Goldstein EJ, Coenye T, Shirtliff ME : Propionibacterium acnes: from commensal to opportunistic biofilm-associated implant pathogen. Clin Microbiol Rev 27 : 419-440, 2014

2. Bicknell $P G$ : Sensorineural deafness following myringoplasty operations. J Laryngol Otol 85 : 957-961, 1971

3. Borgbjerg BM, Gjerris F, Albeck MJ, Borgesen SE : Risk of infection after cerebrospinal fluid shunt: an analysis of 884 first-time shunts. Acta Neurochir (Wien) $136:$ 1-7, 1995

4. Chiou CC, Wong TT, Lin HH, Hwang B, Tang RB, Wu KG, et al. : Fungal infection of ventriculoperitoneal shunts in children. Clin Infect Dis 19 : 1049-1053, 1994

5. Darouiche RO, Wall MJ Jr, Itani KM, Otterson MF, Webb AL, Carrick MM, et al. : Chlorhexidine-alcohol versus povidone-lodine for surgical-site antisepsis. N Engl J Med 362 : 18-26, 2010

6. Davis SE, Levy ML, McComb JG, Masri-Lavine L : Does age or other factors influence the incidence of ventriculoperitoneal shunt infections? Pediatr Neurosurg 30 : 253-257, 1999

7. Felbaum D, Syed HR, Snyder R, McGowan JE, Jha RT, Nair MN : Surgical adhesive drape (IO-ban) as postoperative surgical site dressing. Cureus 7 : e394, 2015

8. George R, Leibrock L, Epstein $M$ : Long-term analysis of cerebrospinal fluid shunt infections. A 25-year experience. J Neurosurg 51 : 804-811, 1979

9. Gottardi W : lodine and iodine compounds in Block SS (ed) : Disinfection, Sterilization, and Preservation. ed 6. Philadelphia : Lea \& Febiger, 1991, pp151-166
10. Grice EA, Kong HH, Conlan S, Deming CB, Davis J, Young AC, et al. : Topographical and temporal diversity of the human skin microbiome. Science 324 : 1190-1192, 2009

11. Grice EA, Segre JA : The skin microbiome. Nat Rev Microbiol 9 : 244253, 2011

12. Grover R, Frank ME : Regional specificity of chlorhexidine effects on taste perception. Chem Senses 33 : 311-318, 2008

13. Gutierrez-Murgas Y, Snowden JN : Ventricular shunt infections: immunopathogenesis and clinical management. J Neuroimmunol 276 : 1-8, 2014

14. Hemani ML, Lepor $\mathrm{H}$ : Skin preparation for the prevention of surgical site infection: which agent is best? Rev Urol 11 : 190-195, 2009

15. Henschen A, Olson L : Chlorhexidine-induced degeneration of adrenergic nerves. Acta Neuropathol 63 : 18-23, 1984

16. Jenkinson MD, Gamble C, Hartley JC, Hickey H, Hughes D, Blundell M, et al. : The British antibiotic and silver-impregnated catheters for ventriculoperitoneal shunts multi-centre randomised controlled trial (the BASICS trial): study protocol. Trials $15: 4,2014$

17. Kestle JR, Riva-Cambrin J, Wellons JC 3rd, Kulkarni AV, Whitehead WE, Walker ML, et al. : A standardized protocol to reduce cerebrospinal fluid shunt infection: the hydrocephalus clinical research network quality improvement initiative. J Neurosurg Pediatr 8 : 22-29, 2011

18. Kong HH, Segre JA : Skin microbiome: looking back to move forward. J Invest Dermatol 132(3 Pt 2) : 933-939, 2012

19. Korinek AM, Fulla-Oller $L$, Boch AL, Golmard JL, Hadiji B, Puybasset $L$ : Morbidity of ventricular cerebrospinal fluid shunt surgery in adults: an 8-year study. Neurosurgery 68 : 985-994; discussion 994-985, 2011

20. McClelland S 3rd, Hall WA : Postoperative central nervous system infection: incidence and associated factors in 2111 neurosurgical procedures. Clin Infect Dis 45 : 55-59, 2007

21. McDonnell G, Russell AD : Antiseptics and disinfectants: activity, action, and resistance. Clin Microbiol Rev 12 : 147-179, 1999

22. Nakatsuji T, Chiang HI, Jiang SB, Nagarajan H, Zengler K, Gallo RL : The microbiome extends to subepidermal compartments of normal skin. Nat Commun 4 : 1431, 2013

23. Pirotte BJ, Lubansu A, Bruneau M, Loqa C, Van Cutsem N, Brotchi J : Sterile surgical technique for shunt placement reduces the shunt infection rate in children: preliminary analysis of a prospective protocol in 115 consecutive procedures. Childs Nerv Syst 23 : 1251-1261, 2007

24. Ritz R, Roser F, Morgalla M, Dietz K, Tatagiba M, Will BE : Do antibioticimpregnated shunts in hydrocephalus therapy reduce the risk of infection? an observational study in 258 patients. BMC Infect Dis $7: 38$, 2007

25. Simon TD, Pope CE, Browd SR, Ojemann JG, Riva-Cambrin J, MayerHamblett $\mathrm{N}$, et al. : Evaluation of microbial bacterial and fungal diversity in cerebrospinal fluid shunt infection. PLoS One 9 : e83229, 2014

26. Theophilus SC, Adnan JS : A randomised control trial on the use of topical methicillin in reducing post-operative ventriculoperitoneal shunt infection. Malays J Med Sci 18 : 30-37, 2011

27. Wang KW, Chang WN, Shih TY, Huang CR, Tsai NW, Chang CS, et al. : Infection of cerebrospinal fluid shunts: causative pathogens, clinical fea- 
Skin Preparation for VP Shunt Surgery | Craven CL, et al.

tures, and outcomes. Jpn J Infect Dis 57 : 44-48, 2004

28. Wells DL, Allen JM : Ventriculoperitoneal shunt infections in adult patients. AACN Adv Crit Care 24 : 6-12; quiz 13-14, 2013
29. Zeeuwen PL, Boekhorst J, van den Bogaard EH, de Koning HD, van de Kerkhof PM, Saulnier DM, et al. : Microbiome dynamics of human epidermis following skin barrier disruption. Genome Biol 13 : R101, 2012 